\title{
Tracking Narratives that are Shaping Our World
}

\author{
Chris D Beaumont ${ }^{1 *}$, John Ricketts ${ }^{2}$ and Darrell Berry ${ }^{2}$ \\ ${ }^{1}$ Institute for Future Initiatives, LifeStyle by Design, The University of Tokyo, Japan \\ ${ }^{2}$ Significance Systems, Sydney NSW 2069, Australia
}

Submission: January 15, 2021; Published: January 22, 2021

*Corresponding author: Chris D Beaumont, Institute for Future Initiatives, LifeStyle by Design, The University of Tokyo, 7-3-1 Hongo, Bunkyo-Ku, Tokyo 113-0033, Japan

\section{Abstract}

In this mini review we present the foundation of how one can track narratives and 'engage with engagement'. We believe explicitly that popular stories affect individual and community behavior. Adopting this approach will improve decision-making by addressing what people feel is important to them with the ability to provide the relevant content, and appropriate tone, which enhances and sustains the on-going narrative.

Keywords: Narratives; Utility; Social sharing; Engagement; Behaviour

\section{Introduction}

Digital technology has transformed many industries, and perhaps most significantly has empowered individuals, through social sharing. People trust people! Our world is online. Narratives and social media are integral parts of today's connected world. They provide echo chambers/media bubbles that provide a lens to understanding (changing) values and behavior.

The diffusion of new ideas and sustainable conversations amongst communities is greatly enhanced by the almost ubiquitous participation in social media in the mature markets around the world, creating the most efficient and effective distribution system. In this regard, Nobel laureate Shiller [1] has recently shown how when contagious stories go viral, they can drive major economic events. He has coined the phrase "Narrative Economics", which is aligned with the notions expressed in "Sustainable Communication" [2]. Social media and social sharing have transformed how our connected world has become entangled. It contrasts sharply with the largely top-down and Western attitude regarding traditional mass-media. This new digital globalism fuels a diversity of viewpoints [3], and the need for deeper awareness of the impact of different cultures.

\section{Approach}

For this reason, The University of Tokyo's LifeStyle by Design Research Unit initiated an investigation, in Jun 2019, of some narratives that aligned with the Unit's mission to explore a holistic lifestyle design that can contribute to improved personal well-
being/QOL. The original premise was to understand what people wanted and that would enable innovation to magnify and annex on-going trends. Beyond creating a benchmark of attitudes and behavior, to monitor the mood of society, it was also intended to be comparative in nature focusing on both Japan and the UK, to help affect policy or monitor any subsequent action plan. As self-medication and healthy lifestyle choices become increasingly important social sharing of new ideas and practices that go viral will have the potential to drive major behavioral shifts. Traditional consumer/market research is by its' very nature akin to looking in the rear-view mirror while driving. A different approach adopted for LifeStyle by Design to explicitly extract insights from on-going global narratives. To do this, the LifeStyle by Design Research Unit chose Significance System's proven and proprietary platform earth.ai to create a Virtual Living Lab [4]. It analyses millions of behavioural interactions with content, to model human interaction, and to provide an objective read on engagement, media power, and the authentic, emotional drivers of (new) behaviour. It can sense and quantify over 400 named emotional states, in response to any story. The process considers all open data online as contending for consideration.

Significance Systems follow a computational-reductionist approach applying multiple layers of processing to identify and extract human-meaningful social-signaling structure within the petabytes of raw topical data available to the first stages of our process. This process dramatically reduces the volume of data to 
which they then apply computationally intensive processes such as detailed grammatical analysis. Understanding of the emotional depth of the narrative, allows for better understanding and connection with people, and focus on leveraging the strong story (Figure 1).
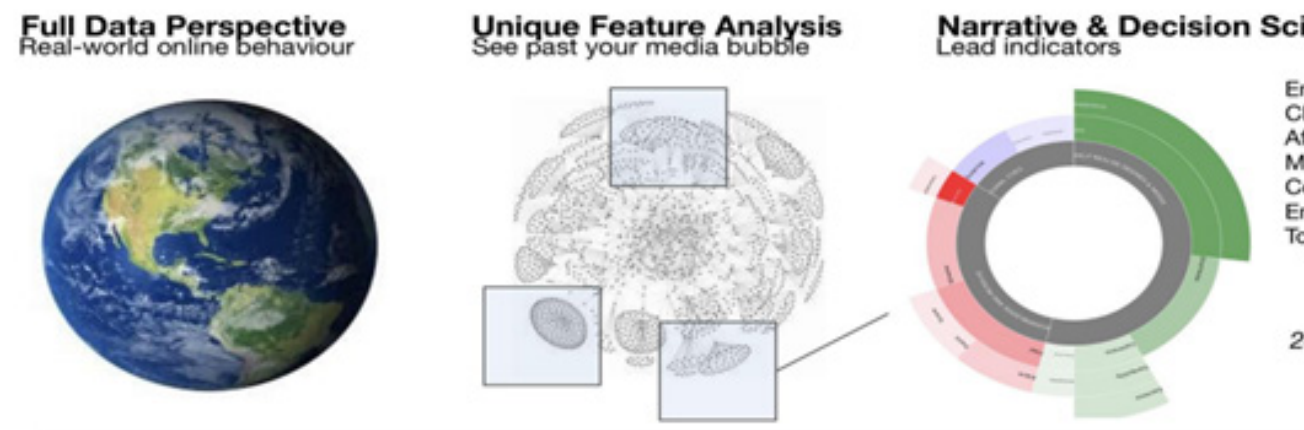

Engagement

Affect Orientation

Aflect Orientation

Content Power

Emotional Response

Topics and Themes

245-dimensions

\section{earth.ai}

\section{Proprietary Machine Learning}

\section{Lifestyle Foresight}

Figure 1: Significance Narrative Assessment @Significance Systems.

Thus, it is now possible, with data-based communications insight, to;

a) objectively explore these narratives to understand the drivers and dynamics of changing behavior and consensus.

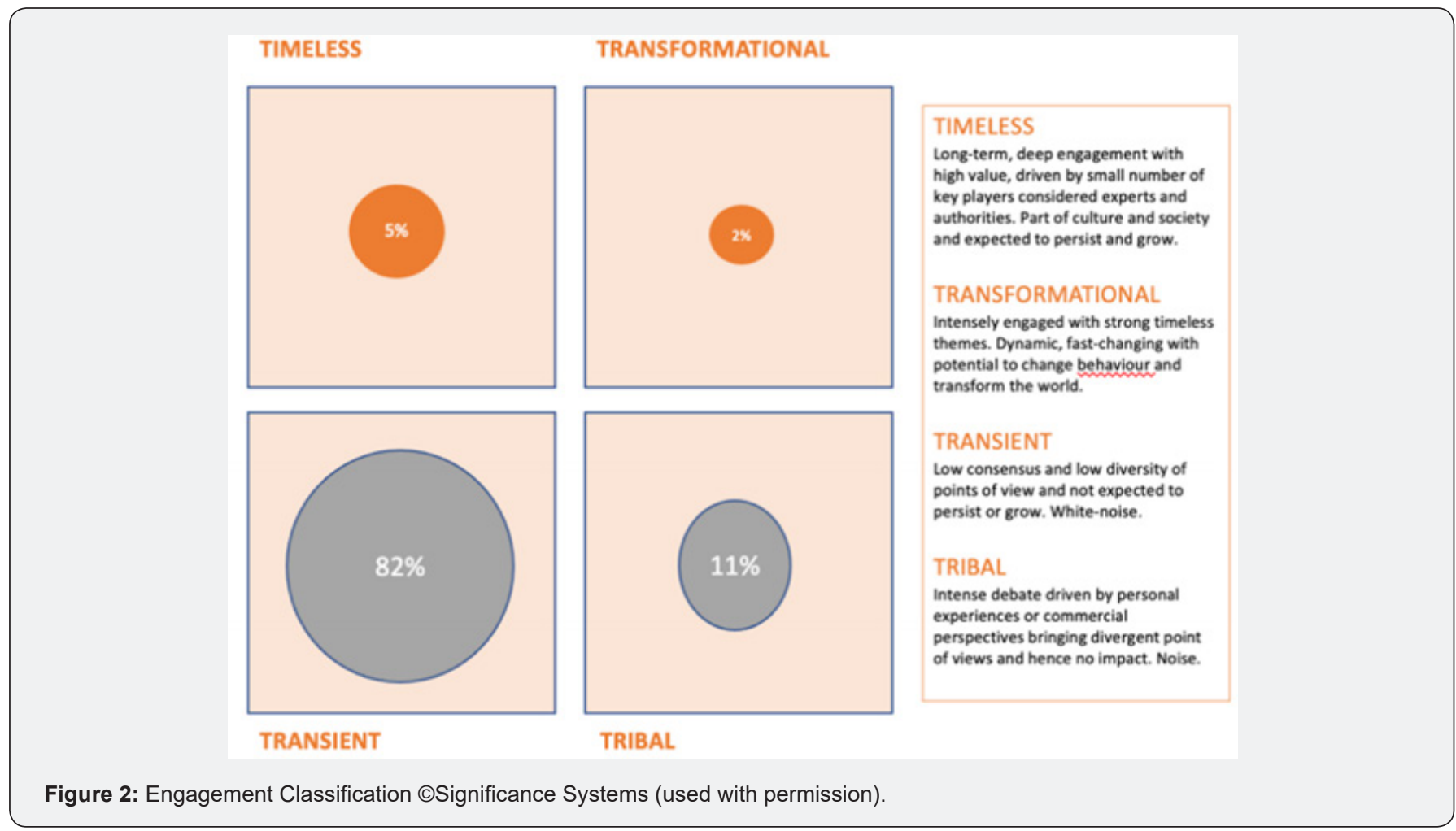

Most internet exchanges are white-noise and thus most narratives, unless harnessed, are Transient (82\%); having low b) probe what people value and feel are more important.

c) establish how new solutions can be effectively introduced to create new and better future behaviours (Figure 2). 
such narratives are often easy to 'own', but they must be driven, or connected to greater relevance and/or differentiation, to have any long-term value. Tribal (11\%) narratives are characterised by intense debate, being driven by personal experiences or commercial perspectives, bringing divergent POVs. The vast majority of this debate, therefore, has no impact. Although it is easy to be a participant, it is far more difficult to be a player or leader in such narratives. Those narratives that have the greatest potential utility are Transformational and Timeless. Transformational (2\%) narratives are characterised by intensely, engaged experiences with strong timeless themes. These narratives are fast-changing, yet potentially result in lasting transformation of the world. Timeless (5\%) narratives are expected to persist or grow. They are characterised by long-term, deep engagement These narratives are good choices for communication activities. If one considers the narratives of the Lifestyle Foresight top 100 brands/companies then their effective communications strategies are focused. One sees Timeless engagement representing at least 90 percent of the narratives [5].

\section{Virtual Living Lab}

To 'engage with engagement' it is not simply having the appropriate content, but it is also critical to convey the appropriate tone. This is dramatically illustrated by the emotional dynamics at a time of perceived vulnerability/uncertainty during 2020 global pandemic, when it is evident that, with conflicting policy options, unclear and sometimes contradictory messages only exacerbated the difficult situation. Figure 3 shows the affect associated with covid-19 from March 2020 when the country went into the first lockdown through to Christmas Day.

Affect is a rich measure of the emotional tone of the narrative. It is felt emotion which is a powerful descriptor of future behaviour. Below the horizontal we see negative emotions dominating the positive senses (above the vertical). Initial panic (red) was replaced by fear, grief, despair and resignation, and material periods of confusion and anger. People's resilience (above the vertical) came through with a greater sense of belonging helping to maintain hope and create optimism. One clear learning in coping with the pandemic has been the need to have a positive outlook. The anxiety, indeed, anger, has been exacerbated by confusing, contradictory messages and as noted in The Guardian [6], confusion, with lockdown rules changing over 60 times, in 9 months since March 2020 (Figure 3).

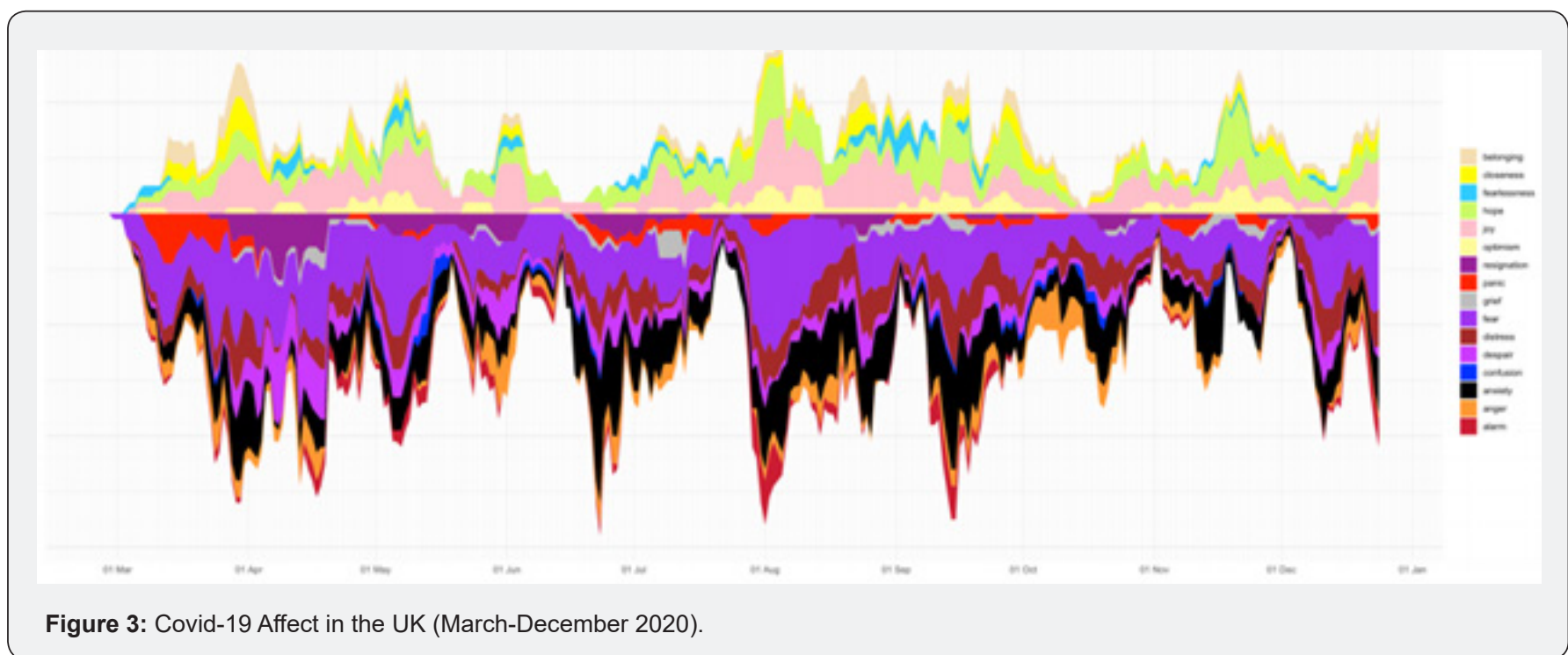

\section{Discussion}

Since people find trusted voices in their networks, this type of analysis enables one to 'engage with engagement' and be part of the on-going story rather than to try to dominate it from outside, which has been the traditional mass communication norm of intrusion.

To effect change any initiatives must engage in a relevant and credible manner, with narratives that are Timeless and Transformative. At the outset we should stress that these analyses are not just identifying some interesting things but things that are really important to people now! So, from a corporate or policy perspective aligning with stories that the people feel are driving their current feelings is important to take a relevant Thought Leadership stance.

\section{References}

1. Shiller J (2019) Narrative Economics: How Stories Go Viral and Drive Major Economic Events. Princetown University Press, USA.

2. Elving WJL (2020) Sustainable Communication. Int J Environ Sci Nat Res 26(3): 556190.

3. Riley C (2017)After the Mass-Age; Analog: Norwood, MA, USA, (In English and Japanese). 
4. Beaumont CD, Ricketts JA (2020) Significant Moment in History: A Virtual Living Lab. LifeStyle Narratives That Are Shaping Our World; the Cases of Japan and UK 2019-2020. Sustainability 12(22): 9658.

5. Significance Systems: Big Data analyses.
6. The Guardian (2021) English Covid rules have changed 64 times since March, says barrister.
Your next submission with Juniper Publishers will reach you the below assets

- Quality Editorial service

- Swift Peer Review

- Reprints availability

- E-prints Service

- Manuscript Podcast for convenient understanding

- Global attainment for your research

- Manuscript accessibility in different formats

( Pdf, E-pub, Full Text, Audio)

- Unceasing customer service

Track the below URL for one-step submission https://juniperpublishers.com/online-submission.php 